\title{
Can Tumour Volume Percentage in Radical Prostatectomy Predict Cancer Biochemical Recurrence? Determining a Cut-off Point and Composite Risk Factors Approach
}

\author{
Ahmad Alenezi $\mathbb{D}^{\prime}$ \\ Mohamed Ismail ${ }^{2}$ \\ Christopher Eden ${ }^{3}$ \\ 'Department of Urology, Mubarak \\ Hospital \& Sabah Al Ahmad Urology \\ Centre, Kuwait City, State of Kuwait; \\ ${ }^{2}$ Department of Urology, Queen \\ Alexandra Hospital, Portsmouth, UK; \\ ${ }^{3}$ Department of Urology, Royal Surrey \\ County Hospital, Guildford, UK
}

Background: Incidence of biochemical recurrence (BCR) after radical prostatectomy is relatively high and overall survival can be poor. Debate exists whether tumour volume predicts BCR and when treatments should be administered. In this study, we aimed to i) assess the impact of tumour volume percentage (TVP) as a predictor for $\mathrm{BCR}$, ii) determine TVP cut-off point for BCR and iii) evaluate single and composite predictors of BCR.

Methods: From March 2000 to December 2013, 1777 patients underwent laparoscopic radical prostatectomy for localized prostate cancer. None received neoadjuvant or adjuvant therapy. One hundred and forty-six patients experienced BCR (range 3 months-10 years). Using D'Amico classification, 146 matched controls without BCR were compared. Liu cut-point analysis was used to identify TVP with optimal sensitivity and specificity. Single and composite BCR risk predictors were analyzed using Cox hazards regression in cases and controls.

Results: Median TVP was 10\% (range 1-90\%). Most of BCR peaked after 3 years of followup. TVP $\geq 8 \%$ was an independent predictor of BCR with HR $1.6(\mathrm{p}=0.001,95 \% \mathrm{CI}=1.11-$ $2.48)$. TVP of $8 \%$ was associated with the highest accuracy: sensitivity $74 \%$ and specificity $53 \%$ (ROC curve $=0.7$ ). At TVP $\geq 8 \%$, pathological stage pT3 was associated with 1.7 -fold higher risk of BCR compared to T2. Lymph node invasion was associated with 1.4-fold higher risk of BCR compared to no invasion. Combining TVP $\geq 8 \%$, pT3 and lymph node invasion, HR jumped to $3.73(\mathrm{p}<0.001,95 \% \mathrm{CI}=2.27-6.14)$, whereas combining TVP $\geq 8 \%$, positive surgical margin and lymph node invasion, HR was $2.68(\mathrm{p}=001,95 \% \mathrm{CI}=1.50-4.77)$.

Conclusion: TVP can be used as an independent predictor of BCR after radical prostatectomy for prostate cancer. TVP cut-point of $\geq 8 \%$ allows the best discrimination. TVP should be considered in combination with other clinico-pathological factors to improve prediction of long-term oncological outcomes and to stratify BCR risk.

Keywords: prostate cancer, predict biochemical recurrence, radical prostatectomy, tumour volume percentage

\section{Introduction}

Radical prostatectomy (RP) has been recognized as the standard management of localized prostate cancer. Estimation of recurrence risk is paramount for specific management and investigating new trials. Incidence of biochemical recurrence (BCR) is relatively high (approximately 30\% of patients) and overall survival can be poor. Debate exists whether tumour volume is predictor of BCR and when treatments should be started after BCR. ${ }^{1}$ In spite of the highly sensitive screening 
test by serum prostate-specific antigen (PSA) and recent advances in surgical techniques, post-surgery recurrence has been recorded in at least $20 \%$ of all patients. ${ }^{2,3}$ Observation of an elevated PSA after a RP is considered the first sign of biochemical recurrence (BCR). Natural history of cancer progression includes either local recurrence or distant metastasis, the PSA doubling time being correlated with the development of metastatic disease. ${ }^{4}$

Along with post-operative PSA, several independent factors were developed in order to estimate the risk of BCR, such as the type of surgical operation, Gleason score, tumour stage and surgical margin (SM) status. ${ }^{5}$ In addition, there has been a debate on whether tumor volume can be considered an additional parameter for evaluation of tumor behavior. ${ }^{6}$ In 2006, Nelson et al concluded that tumour volume correlated directly with the pathological stage of RP specimens, and also with the post-operative PSA increase. ${ }^{7}$ Although this study was limited by small sample size and short follow-up, the authors hypothesized that tumor volume could be a possible prognostic tool together with the standard prediction values. ${ }^{7}$ Another recent study revealed that either the total tumour volume or maximum tumour diameter could add a significant value in prediction of tumor recurrence. ${ }^{8}$ Tumour volume percentage (TVP), also known as tumour percent cancer, that is the percentage of prostate volume involved with tumour (tumour volume/prostate volume), has been firstly proposed as a predictor of recurrence-free survival after RP together with preoperative PSA and Gleason score. ${ }^{9}$ More recently, TVP was shown to be a predictor of both extra-prostatic extension and BCR after RP. ${ }^{10}$ However, more studies are recommended to build conclusive evidence. Moreover, it is still debated whether or not TVP or just tumour volume is more efficient for prognostication after RP. ${ }^{11}$ In a meta-analysis on 15 studies, Meng et al found that both tumour volume and TVP were significantly associated with BCR after $\mathrm{RP}$, with a combined hazard ratio of 1.04 and 1.01, respectively. ${ }^{12}$

Finally, an interesting novel approach for BCR prediction is the volumetric quantification of tumour burden by calculating radiotracer avidity. ${ }^{13,14}$

In this retrospective study, we aimed to i) assess the impact of tumour volume percentage (TVP) as a predictor for BCR after RP, ii) determine TVP cut-off point according to $\mathrm{BCR}$ risk, and iii) evaluate single and composite predictors of $\mathrm{BCR}$.

\section{Methods}

We retrospectively identified 1777 patients who had undergone RP for localized prostate cancer from March 2000 through December 2013. Institutional Review Board (IRB) was waived by Royal Surrey County Hospital because of its retrospective nature, clinical purpose and no procedure is required. Informed Consent was obtained from all participants prior to the study. This study was conducted in accordance with the Declaration of Helsinki.

Patients' records were reviewed to obtain demographic and clinical data. Surgical margin was considered positive if the tumour extended to the edges of specimens on histological examination. Dissected lymph nodes were examined histologically to look for tumor invasion. TVP was measured by using a ruler, graph paper and multiplication factor for the block thickness. All specimens were completely sectioned and examined histologically, and for each specimen, the percentage of tumour was estimated by visual inspection and for each slide of prostate the percentage of the area occupied by tumour was estimated. Clinical staging and Gleason grade were assigned to the attending urologist. Pathological staging was performed by the attending pathologist through haematoxylin and eosin-staining, according to standard criteria. PSA at baseline was noted and its values were followed up to two years. According to the American Urological Association (AUA), ${ }^{35}$ BCR was defined as a PSA value $\geq 0.2 \mathrm{ng} / \mathrm{mL}$ followed by a subsequent confirmatory value $\geq 0.2 \mathrm{ng} / \mathrm{mL}$. We excluded patients who received neo-adjuvant, adjuvant therapy, hormonal or radiation therapy. A control group $(n=146)$ matched for D'Amico score was created for comparison. Matching method was performed by propensity score matching and stratification for recurrence (Figure 1).

Descriptive statistics was performed to determine the distribution of categorical or continuous variables by calculating number with frequency (\%), or median with range, respectively. Chi-square test or the Fisher's exact test and paired $t$-test were calculated for categorical and continuous variables, respectively. One-way ANOVA was used to assess the correlation between the tested parameters. In order to identify TVP value with optimal sensitivity and specificity, Liu cut-point analysis was used. In both groups, we also used a multivariable Cox proportional hazards model adjusted for age, summation of pathological Gleason score, preoperative PSA, positive surgical margin status, pathological stage and lymph 
1,777 patients who had undergone radical prostatectomy from March 2000 through December 2013

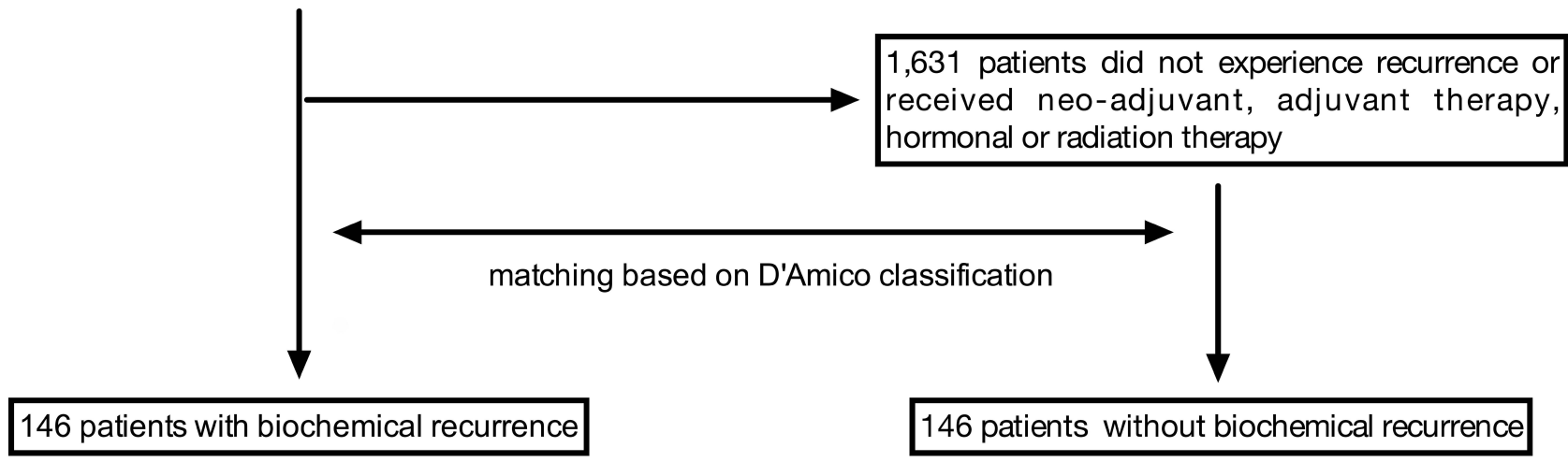

Figure I Propensity score matching and stratification for recurrence.

node invasion. Two subsequent Cox proportional hazards models were then created, including the linear predictor to represent current predictors. All analyses were performed using Stata version 14 (StataCorp, College Station, Texas). The level of significance was set at $\mathrm{P} \leq 0.05$.

\section{Results}

\section{Patients and Disease Characteristics (Table I)}

One hundred and forty-six patients who experienced BCR recurrence after RP were compared with 146 patients who did not experience disease recurrence and who were matched based on D'Amico classification, the latter being an estimate of the 5-year recurrence risk calculated based on three preoperative parameters: PSA level, biopsy Gleason score and tumour stage. ${ }^{15}$ Cases were significantly older than controls (median age 64 vs 62 years). Clinical stage in the case group was mostly an early one, $\mathrm{T} 2 \mathrm{a}(\mathrm{n}=40,27.0 \%)$ and $\mathrm{T} 1 \mathrm{c}$ in $(\mathrm{n}=32,21.9 \%)$, while in the control group the most frequent stage was $\mathrm{T} 1 \mathrm{c}$, which was found in approximately half of patients $(\mathrm{n}=66,45.2 \%)$, followed by $\mathrm{T} 2 \mathrm{c}$ in $24 \%$. However, pathological (p) stage was higher than clinical stages, $79 \%$ of case group and $76 \%$ of control group having from $\mathrm{pT} 2 \mathrm{c}$ through $\mathrm{pT} 3 \mathrm{~b}$. Overall, cases had more advanced disease compared to controls expressed either as clinical or as pathological stage $(\mathrm{P}<0.0001$ and $\mathrm{P}=$ 0.0002).

Median preoperative PSA was higher in case group than control group $[9.9 \mathrm{ng} / \mathrm{mL}(1-253)$ vs $8.0(1-31), \mathrm{P}=$
0.003]. The majority of patients in both groups demonstrated a Gleason score of $7[n=86(58.9 \%)$ patients in the case group and 78 (53.4\%) in the control group] and a high D'Amico score, ie Gleason score $>8$ or PSA $>20 \mathrm{ng} / \mathrm{mL}$ or clinical stage $\geq T 2 c \quad[n=68$ patients $(48.6 \%)$ in both groups]. Median follow-up duration was longer for controls compared to cases (48 vs 30 months, $\mathrm{P}<0.0001$ ).

In the case group, median prostate weight was 51.5 grams (20-153) and median TVP was 15\% (range: 0 $80 \%)$. In the control group, the corresponding values were 55 grams (range: 23-450) and 7.5\% (range: 1-90), respectively. Of note, statistical significant difference was found only regarding TVP $(\mathrm{P}<0.001)$.

Positive surgical margin in the case group was reported in 64 patients $(43.8 \%)$ vs 29 patients $(19.9 \%)$ in the control group. Lymph node involvement was found at histology in 34 cases $(23.3 \%)$, but only in 5 controls $(3.4 \%)(\mathrm{P}<$ $0.0001)$.

To assess the effect of pathological staging in relation to TVP, statistical significant difference among different pathological staging was found in case group $(\mathrm{P}=0.0005)$ in contrast to the control group $(\mathrm{P}=0.10)$.

\section{The Univariable and Multivariable Analyses}

At univariate analysis, to assess whether some independent factors could increase or decrease the risk of BCR, TVP, age, pathological Gleason score, positive surgical margin and pT3 were strongly correlated with the probability of progression Table 2. Composites, predictors and covariates 
Table I Summary of Patients and Disease Characteristics

\begin{tabular}{|c|c|c|c|c|c|}
\hline Parameter & $\begin{array}{l}\text { Control Group (N } \\
=\mid 46)\end{array}$ & $\begin{array}{l}\text { Case Group } \\
(N=\mid 46)\end{array}$ & $\begin{array}{l}\text { Chi- } \\
\text { Square }\end{array}$ & $\begin{array}{l}\text { Degrees of } \\
\text { Freedom }\end{array}$ & $P$ values \\
\hline Age (years) & $62(4 \mid-75)$ & $64(46-76)$ & - & - & 0.019 \\
\hline $\begin{array}{l}\text { Clinical stage (\%) } \\
\text { T1c } \\
\text { T2a } \\
\text { T2b } \\
\text { T2c } \\
\text { T3a } \\
\text { T3b } \\
\text { Missing }\end{array}$ & $\begin{array}{l}66(45.2 \%) \\
28(19.2 \%) \\
6(4.1 \%) \\
35(24.0 \%) \\
7(4.8 \%) \\
3(2 \%) \\
I(0.7 \%)\end{array}$ & $\begin{array}{l}32(21.9 \%) \\
40(27.3 \%) \\
20(13.7 \%) \\
28(19.1 \%) \\
16(10.95 \%) \\
8(5.5 \%) \\
2(1.4 \%)\end{array}$ & 35.73 & 6 & $<0.0001$ \\
\hline $\begin{array}{l}\text { Pathological stage (\%) } \\
\text { T1c } \\
\text { T2a } \\
\text { T2b } \\
\text { T2c } \\
\text { T3a } \\
\text { T3b } \\
\text { Missing }\end{array}$ & $\begin{array}{l}\text { I }(0.7 \%) \\
16(10.95 \%) \\
13(8.9 \%) \\
73(50 \%) \\
24(16.4 \%) \\
14(9.6 \%) \\
5(3.4 \%)\end{array}$ & $\begin{array}{l}0 \\
10(6.8 \%) \\
17(11.6 \%) \\
43(29.4 \%) \\
28(19.1 \%) \\
44(30.1 \%) \\
4(2.7 \%)\end{array}$ & 21.61 & 6 & 0.0002 \\
\hline Preoperative PSA $(\mathrm{ng} / \mathrm{mL})$ & $8.0(\mid-3 I)$ & $9.9(I-253)$ & - & - & 0.003 \\
\hline $\begin{array}{l}\text { Gleason score (\%) } \\
5 \\
6 \\
7 \\
8 \\
9 \\
10 \\
\text { Missing }\end{array}$ & $\begin{array}{l}\text { I }(0.7 \%) \\
57(39 \%) \\
78(53.4 \%) \\
4(2.7 \%) \\
3(2 \%) \\
\text { I (0.7\%) } \\
2(1.4 \%)\end{array}$ & $\begin{array}{l}0 \\
25(17.1 \%) \\
86(58.9 \%) \\
13(8.9 \%) \\
17(11.6 \%) \\
0 \\
5(3.4 \%)\end{array}$ & 30.73 & 6 & $<0.0001$ \\
\hline $\begin{array}{l}\text { D'Amico classification (\%) } \\
\text { Low } \\
\text { Intermediate } \\
\text { High } \\
\text { Mean follow up (months) }\end{array}$ & $\begin{array}{l}23(15.7 \%) \\
55(37.7 \%) \\
68(46.6 \%) \\
48(36-120)\end{array}$ & $\begin{array}{l}23(15.7 \%) \\
55(37.7 \%) \\
68(46.6 \%) \\
30(3-120)\end{array}$ & 0 & - & $\begin{array}{l}\text { I } \\
<0.0001\end{array}$ \\
\hline Prostate weight (g) & $55.0(23-450)$ & $51.5(20-153)$ & - & - & 0.1875 \\
\hline Tumour volume percent & $7.5(I-90)$ & $15.0(0-80)$ & - & - & $<0.0001$ \\
\hline $\begin{array}{l}\text { Surgical Margin (\%) } \\
\text { Positive } \\
\text { Negative }\end{array}$ & $\begin{array}{l}29(19.9 \%) \\
117(80.1 \%)\end{array}$ & $\begin{array}{l}64(43.8 \%) \\
82(56.2 \%)\end{array}$ & 19.33 & I & $<0.0001$ \\
\hline $\begin{array}{l}\text { Lymph Node Dissection } \\
\text { Invaded with cancer } \\
\text { Not invaded with cancer } \\
\text { Lymph Node Dissection not } \\
\text { performed }\end{array}$ & $\begin{array}{l}48(32.9 \%) \\
5(3.4 \%) \\
43(29.4 \%) \\
98(67.1 \%)\end{array}$ & $\begin{array}{l}69(47.3 \%) \\
34(23.3 \%) \\
35(24.0 \%) \\
77(52.7 \%)\end{array}$ & $\begin{array}{l}6.289 \\
-\end{array}$ & $\begin{array}{l}\text { I } \\
-\end{array}$ & $\begin{array}{l}0.0121^{*} \\
<0.000 I^{* *}\end{array}$ \\
\hline
\end{tabular}

Notes: *Lymph node dissection vs lymph node dissection not performed. **Lymph node invaded with cancer vs Lymph node not invaded with cancer (by the Fisher's exact test). 


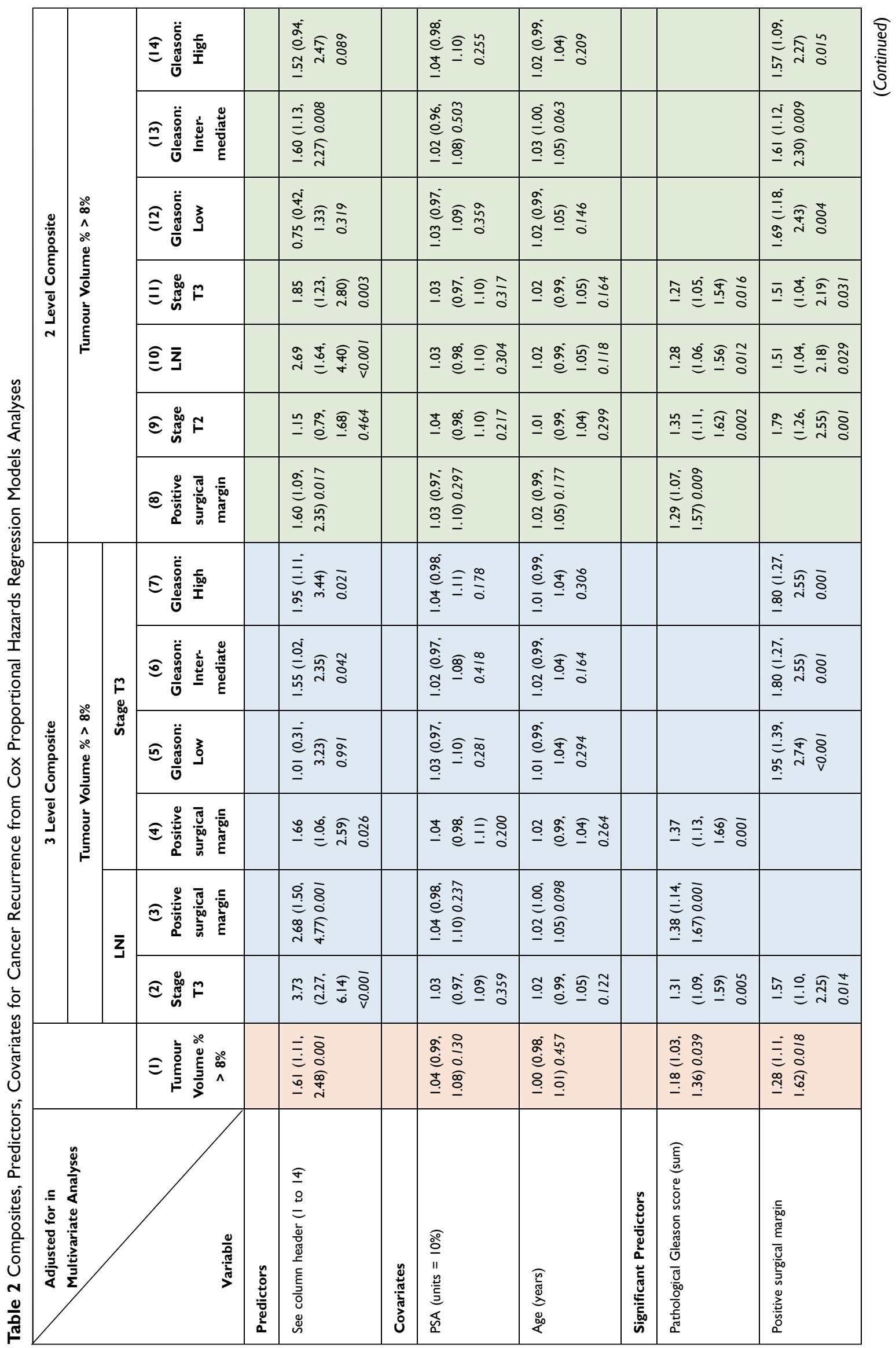




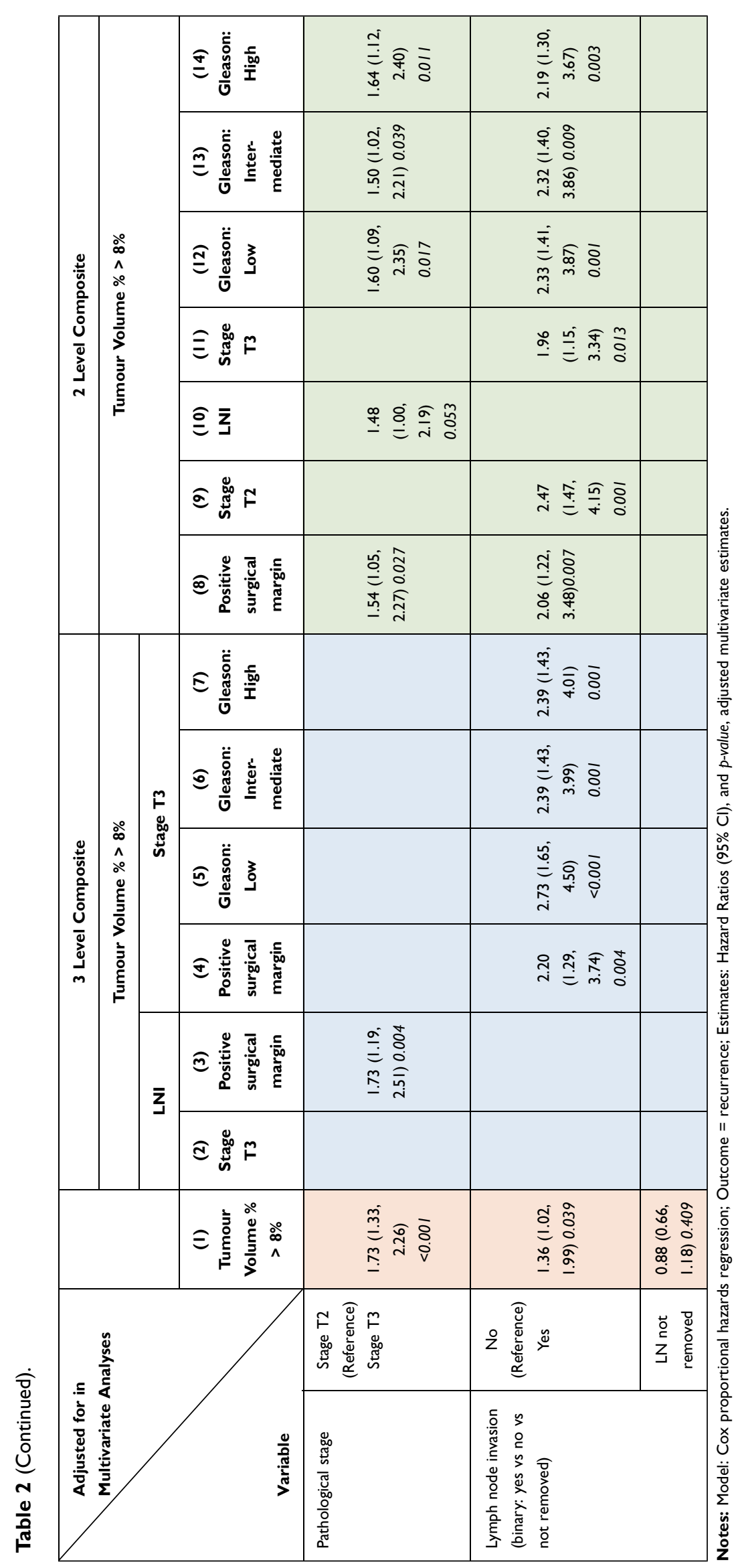




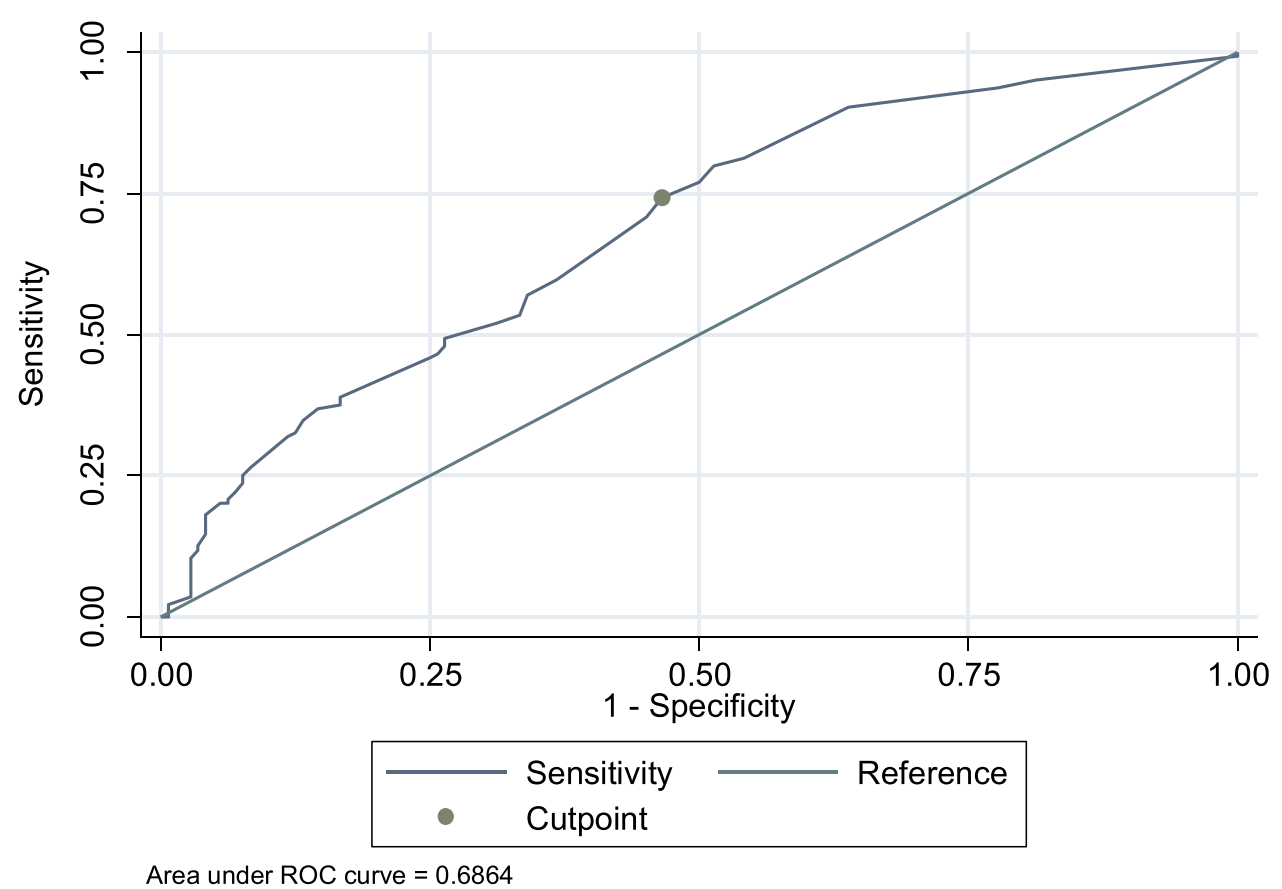

Figure 2 A receiver operating characteristic (ROC) curve for sensitivity and specificity of tumour volume percentage values.

for BCR from Cox proportional hazards regression models analysis are provided in Table 2.

Multivariate analyses showed that the median TVP was $10 \%(1-90 \%)$ and TVP $\geq 8 \%$ (optimal cut-point) was a significant independent predictor of BCR with hazard ratio $(\mathrm{HR})=1.6[95 \%$ confidence interval $(\mathrm{CI})=1.11-$
2.48, $\mathrm{P}<0.001]$. A receiver-operating characteristic (ROC) curve for this cut off value ( $8 \%$ ) yielded sensitivity and a specificity of $74 \%$ and $53 \%$, respectively (Figure 2).

Patients with TVP $<8 \%$ were more frequently recurrence-free at 5 years compared to patients with TVP $\geq 8 \%$ (Figure 3).

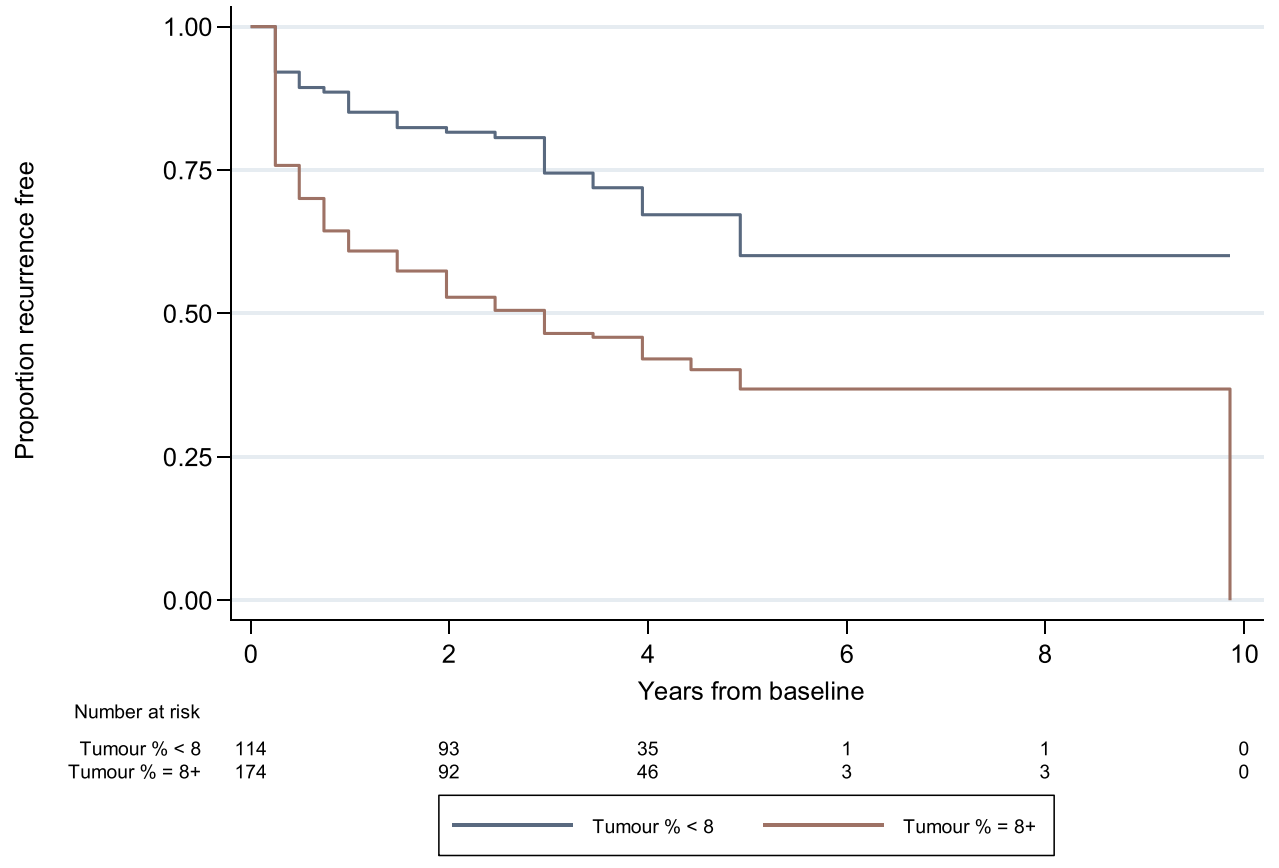

Figure 3 Proportion of recurrence-free patients according to tumor volume percentage. 


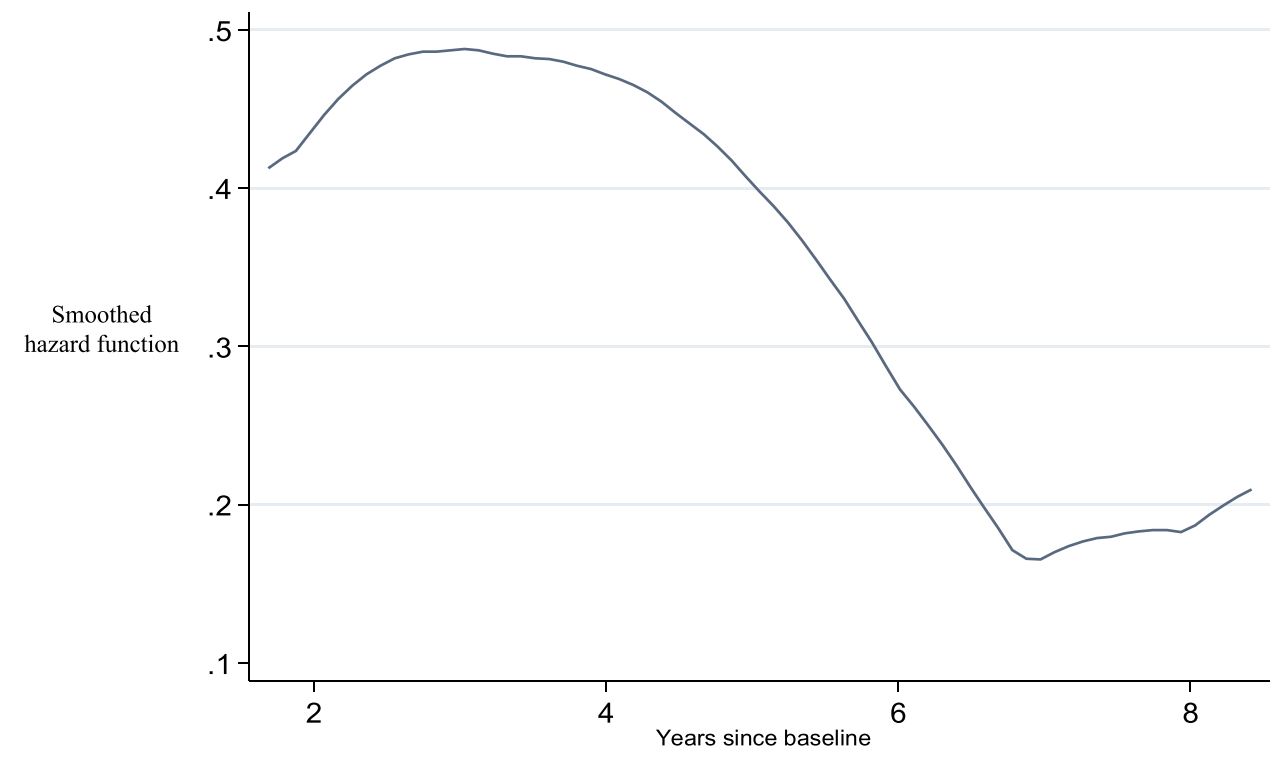

Figure 4 Risk of disease recurrence peaks obtained by smoothed hazard function.

Pathological Gleason score and positive surgical margin were associated with increased risk of $\mathrm{BCR}(\mathrm{HR}=1.18$ and 1.28, respectively). pT3 was also associated with a 1.7-fold higher risk $(95 \% \mathrm{CI}=1.33-2.26)$ of $\mathrm{BCR}$ compared to pT2. Regarding lymph node dissection, lymph node invasion was associated with 1.4. Fold higher risk $(95 \% \mathrm{CI}=1.02-1.99, \mathrm{P}=0.039)$ of $\mathrm{BCR}$ compared to no invasion. No age or PSA value raised the risk of BCR. Combining these three risk factors, namely TVP $\geq 8 \%$, pT3 and lymph node invasion, HR jumped to 3.73 ( $\mathrm{p}<0.001$, 95\% CI $=2.27-6.14$ ), whereas combining $\mathrm{TVP} \geq 8 \%$, positive surgical margin and lymph node invasion HR was $2.68(\mathrm{p}=001,95 \% \mathrm{CI}=1.50-4.77)$ (Table 2$)$.

Of note, the highest risk of BCR was found approximately at the third year of follow-up and then subsequently dropped, with another slight increase after the seventh year (Figure 4).

\section{Discussion}

In patients who have undergone RP for prostate cancer, prediction of disease recurrence or BCR is an essential step to determine if adjuvant therapy is required. ${ }^{2}$ In our study, we retrospectively reviewed records of patients who experienced BCR and compared their clinicopathological parameters with those of a control group that did not experience $\mathrm{BCR}$ in order to identify predictive factors of BCR. In this regard, the role of TVP is still controversial. ${ }^{1}$ Currently, in the UK, the Royal College of Pathologists does not support routine TVP estimation in prostatectomy specimens and only broad ranges of percentage of involvement of the specimen is reported. TVP measurement presently is performed upon a specific request.

Our results showed that TVP $\geq 8 \%$ along with pathological Gleason score, positive surgical margin, pT3 and lymph node invasion are independent predictors of BCR. Most importantly, our composite analysis showed that combining TVP with the other prognostic factors significantly increased the prediction of BCR.

To date, management of patients with positive surgical margins and/or lymph node invasion is still debated, as according to physician's preference or institutional practice patterns, watchful observation or adjuvant hormonal therapy can be chosen. Timing and duration of adjuvant therapy is still debated. In the present study, we excluded patients who received neo-adjuvant, adjuvant therapy, hormonal or radiation therapy, and observed the remaining patients over time after RP. ${ }^{1}$

Prostatic epithelial cells produce PSA, which has a 3-day half-life in serum; therefore, 3-4 weeks after RP, its levels should be undetectable. In this regard, ultrasensitive assays could detect residual cancer or disease recurrence by several months. ${ }^{16-18}$ Overall, a PSA cut-off $>0.4 \mathrm{ng} / \mathrm{mL}$ has been proposed as the most appropriate cut-off to diagnose BCR after $\mathrm{RP},{ }^{19,20}$ whereas PSA $>0.2 \mathrm{ng} / \mathrm{mL}$ was associated with a 1 and 3-year risk of PSA progression of $86 \%$ and $100 \%$, respectively. ${ }^{20}$ Ellis et al showed that an ultrasensitive chemiluminescent PSA assay with a cut-off of $0.1 \mathrm{ng} / \mathrm{mL}$ can detect recurrent prostate cancer with significant lead time compared to conventional assays. ${ }^{21}$ 
Increased tumour volume was found to be associated with pathological grading and staging parameters. A number of studies have elucidated the role of tumour volume for $\mathrm{BCR}$ prediction $^{5-7,22}$ especially in pT2 tumours $^{23}$ and in those with Gleason score $\geq 7 .{ }^{22}$ A metaanalysis by Meng et al found that both tumour volume and TVP significantly associated with BCR after RP. ${ }^{12}$ According to this line of evidence, very recently TVP was found to be an independent prognostic factor in the post-operative BCR in a cohort of 2394 patients who had undergone RP for localised prostate cancer. ${ }^{24}$ Finally, Kir has proposed to use TVP as one parameter to be taken into account when considering adjuvant therapy for localized prostate cancer. ${ }^{25}$

However, some other studies concluded that tumour volume does not provide any additional information for BCR prediction. ${ }^{26,27}$ For instance, it has been noted that tumour volume does not add any important predictive accuracy at univariate analysis, at least when it used alone. ${ }^{22,26,27}$ Accordingly, in men with $\mathrm{pT}^{28}$ or pT3-T4 prostate cancer, ${ }^{29}$ the combination of TVP and other clinicopthological variables, such as surgical Gleason score, ${ }^{28,29}$ PSA, surgical margin status and lymphovascular invasion ${ }^{29}$ permitted to improve recurrence risk stratification. In line with these studies, we found that Gleason score and pathological stage are independent factors for predicting disease progression or recurrence after RP. ${ }^{5,28}$ Recently, Ito demonstrated that tumor quantitation metrics, namely the total tumour volume and the maximum tumour diameter are not useful to predict BCR of pT2 prostate cancer. ${ }^{8}$ More generally, by analysing 12,261 patients who underwent RP, the same group showed also that neither 6 prostate metrics including three volumes (prostate volume, total tumour volume, high-grade total tumour volume) and 3 ratios (the ratio of high-grade total tumour volume to total tumour volume, the ratio of total tumour volume to prostate volume and the ratio of high-grade total tumour volume to prostate volume) added discrimination to the standard clinicopathological variables for BCR prediction nor they provided benefit to clinical decision-making. ${ }^{30}$ Therefore, these authors did not recommend reporting these parameters routinely. ${ }^{30}$

Further, there is another controversy regarding standard tumour quantification in RP specimens, as some authors measured tumour volume by streamlined 3-dimensional (length, width, and height) estimation volume formula, which is the current most accepted method, ${ }^{31}$ whereas other authors used visual estimation of the percentage of microscopic invasion of carcinoma in the specimens or 2-dimensional measurement. ${ }^{32}$ In addition, another report revealed that the RP specimens can be stratified by tumour size according to simple assessment of maximum tumour area by using single or multiple slides, as in the routine clinical practice. ${ }^{33}$ Marks et al reported that the ratio of tumor-positive tissue blocks to the total number of blocks could be an independent prognostic indicator for BCR. ${ }^{32}$ Müller et $\mathrm{al}^{34}$ added the maximum tumour diameters of all tumours instead of using only the largest tumour diameter. The authors found that a value $>19.5 \mathrm{~mm}$ was an independent predictor of BCR. ${ }^{34}$ Finally, a recent study comparing two approaches for tumour measurement, namely total tumour volume by planimetry and 2-dimensional maximum tumour diameter by digital ruler, found that they were not useful for prediction of BCR in pT2 prostate cancer. $^{8}$

\section{Limitations}

Similarly to any retrospective single institution analysis, our study has some limitations about the selection of participants with available data. Indeed, even though some data were missing, all reported data were examined. Concerning control matching, the major limitation is the significantly different age between cases and controls.

\section{Conclusion}

TVP can be used as an independent predictor of BCR. TVP cut-point of $\geq 8 \%$ allows the best discrimination for an accurate BCR prediction. TVP should be considered in combination with other clinicopathological prognostic factors to improve prediction of long-term oncological outcomes and to stratify BCR risk. A close follow-up during the first 3 years, in which the peak of BCR is expected, is also recommended. Subsequent reports on large-scale to assess the validation of our results are needed.

\section{Acknowledgment}

The abstract of this paper was presented at the 37th world congress of Endourology as a poster presentation and talk with interim findings only. The poster abstract was not published in any journal.

\section{Disclosure}

The authors report no conflicts of interest in this work. 


\section{References}

1. Thompson IM 3rd, Salem S, Chang SS, et al. Tumor volume as a predictor of adverse pathologic features and biochemical recurrence (BCR) in radical prostatectomy specimens: a tale of two methods. World J Urol. 2011;29(1):15-20. doi:10.1007/s00345-010-0611-x

2. Zincke H, Oesterling JE, Blute ML, Bergstralh EJ, Myers RP, Barrett DM. Long-term (15 years) results after radical prostatectomy for clinically localized (stage T2c or lower) prostate cancer. $J$ Urol. 1994;152(5 Pt 2):1850-1857. doi:10.1016/S0022-5347(17)32399-6

3. Catalona WJ, Smith DS. 5-year tumor recurrence rates after anatomical radical retropubic prostatectomy for prostate cancer. $J$ Urol. 1994;152(5 Pt 2):1837-1842. doi:10.1016/S0022-5347(17)32397-2

4. Pound CR, Partin AW, Eisenberger MA, Chan DW, Pearson JD, Walsh PC. Natural history of progression after PSA elevation following radical prostatectomy. JAMA. 1999;281(17):1591-1597. doi:10.1001/jama.281.17.1591

5. Stamey TA, McNeal JE, Yemoto CM, Sigal BM, Johnstone IM. Biological determinants of cancer progression in men with prostate cancer. JAMA. 1999;281(15):1395-1400. doi:10.1001/ jama.281.15.1395

6. Epstein JI, Carmichael M, Partin AW, Walsh PC. Is tumor volume an independent predictor of progression following radical prostatectomy? A multivariate analysis of 185 clinical stage $B$ adenocarcinomas of the prostate with 5 years of followup. J Urol. 1993;149(6):1478-1481. doi:10.1016/S0022-5347(17)36421-2

7. Nelson BA, Shappell SB, Chang SS, et al. Tumour volume is an independent predictor of prostate-specific antigen recurrence in patients undergoing radical prostatectomy for clinically localized prostate cancer. BJU Int. 2006;97(6):1169-1172. doi:10.1111/ j.1464-410X.2006.06148.x

8. Ito Y, Vertosick EA, Sjoberg DD, et al. In organ-confined prostate cancer, tumor quantitation not found to aid in prediction of biochemical recurrence. Am $J$ Surg Pathol. 2019;43(8):1061-1065. doi:10.1097/PAS.0000000000001291

9. Song C, Seo S, Ahn H, et al. Percent tumor volume predicts biochemical recurrence after radical prostatectomy: multi-institutional data analysis. Int J Clin Oncol. 2012;17(4):355-360. doi:10.1007/ s10147-011-0295-2

10. Hwang EC, Yu SH, Jo YH, et al. Effect of serum testosterone and percent tumor volume on extra-prostatic extension and biochemical recurrence after laparoscopic radical prostatectomy. Asian $J$ Androl. 2016;18(1):54-59. doi:10.4103/1008-682X.154317

11. Chung BI, Tarin TV, Ferrari M, Brooks JD. Comparison of prostate cancer tumor volume and percent cancer in prediction of biochemical recurrence and cancer specific survival. Urol Oncol. 2011;29 (3):314-318. doi:10.1016/j.urolonc.2009.06.017

12. Meng Y, Li H, Xu P, Wang J. Do tumor volume, percent tumor volume predict biochemical recurrence after radical prostatectomy? A meta-analysis. Int J Clin Exp Med. 2015;8(12):22319-22327.

13. Zhou S, Fu H, Liu C, et al. Value of 11C-Choline PET/CT-based multi-metabolic parameter combination in distinguishing early-stage prostate cancer from benign prostate diseases. Front Oncol. 2021;10:600380. doi:10.3389/fonc.2020.600380

14. Santos A, Mattiolli A, Carvalheira JB, et al. PSMA whole-body tumor burden in primary staging and biochemical recurrence of prostate cancer. Eur J Nucl Med Mol Imaging. 2021;48(2):493-500. doi:10.1007/s00259-020-04981-x

15. D'Amico AV, Whittington R, Malkowicz SB, et al. Biochemical outcome after radical prostatectomy, external beam radiation therapy, or interstitial radiation therapy for clinically localized prostate cancer. JAMA. 1998;280(11):969-974. doi:10.1001/jama.280.11.969

16. Polascik TJ, Oesterling JE, Partin AW. Prostate specific antigen: a decade of discovery--what we have learned and where we are going. J Urol. 1999;162(2):293-306. doi:10.1016/S0022-5347(05) 68543-6
17. Partin AW, Oesterling JE. The clinical usefulness of prostate specific antigen: update 1994. $J$ Urol. 1994;152(5 Pt 1):1358-1368. doi:10.1016/S0022-5347(17)32422-9

18. Stamey TA, Kabalin JN, McNeal JE, et al. Prostate specific antigen in the diagnosis and treatment of adenocarcinoma of the prostate. II. Radical prostatectomy treated patients. J Urol. 1989;141 (5):1076-1083. doi:10.1016/S0022-5347(17)41175-X

19. Amling CL, Bergstralh EJ, Blute ML, Slezak JM, Zincke H. Defining prostate specific antigen progression after radical prostatectomy: what is the most appropriate cut point? J Urol. 2001;165 (4):1146-1151. doi:10.1016/S0022-5347(05)66452-X

20. Freedland SJ, Sutter ME, Dorey F, Aronson WJ. Defining the ideal cutpoint for determining PSA recurrence after radical prostatectomy. Prostate-specific antigen. Urology. 2003;61(2):365-369. doi:10.1016/ S0090-4295(02)02268-9

21. Ellis WJ, Vessella RL, Noteboom JL, Lange PH, Wolfert RL, Rittenhouse HG. Early detection of recurrent prostate cancer with an ultrasensitive chemiluminescent prostate-specific antigen assay. Urology. 1997;50(4):573-579. doi:10.1016/S0090-4295(97)00251-3

22. Merrill MM, Lane BR, Reuther AM, Zhou M, Magi-Galluzzi C, Klein EA. Tumor volume does not predict for biochemical recurrence after radical prostatectomy in patients with surgical Gleason score 6 or less prostate cancer. Urology. 2007;70(2):294-298. doi:10.1016/j. urology.2007.03.062

23. Choi SY, Chi BH, Lim B, et al. Percent tumor volume vs American Joint Committee on Cancer staging system subclassification for predicting biochemical recurrence in patients with pathologic T2 prostate cancer. J Cancer Res Clin Oncol. 2020;146(2):537-543. doi:10.1007/s00432-019-03085-w

24. Yuk HD, Byun S, Hong SK, Lee H. Evaluation of the tumor volume from surgical specimens after radical prostatectomy and its clinical impact on the prognosis of patients with localized prostate cancer. Res Square. 2021. doi:10.21203/rs.3.rs-130026/v1

25. Kir G, Arikan EA, Seneldir H, et al. Determining the cut-off values of tumor diameter, degree of extraprostatic extension, and extent of surgical margin positivity with regard to biochemical recurrence of prostate cancer after radical prostatectomy. Ann Diagn Pathol. 2020;44:151431. doi:10.1016/j.anndiagpath.2019.151431

26. Salomon L, Levrel O, Anastasiadis AG, et al. Prognostic significance of tumor volume after radical prostatectomy: a multivariate analysis of pathological prognostic factors. Eur Urol. 2003;43(1):39-44. doi:10.1016/S0302-2838(02)00493-1

27. Kikuchi E, Scardino PT, Wheeler TM, Slawin KM, Ohori M. Is tumor volume an independent prognostic factor in clinically localized prostate cancer? J Urol. 2004;172(2):508-511. doi:10.1097/01. ju.0000130481.04082.1a

28. Song C, Kang T, Yoo S, et al. Tumor volume, surgical margin, and the risk of biochemical recurrence in men with organ-confined prostate cancer. Urol Oncol. 2013;31(2):168-174. doi:10.1016/j. urolonc.2010.11.005

29. You D, Jeong IG, Song C, et al. High percent tumor volume predicts biochemical recurrence after radical prostatectomy in pathological stage T3a prostate cancer with a negative surgical margin. Int J Urol. 2014;21(5):484-489. doi:10.1111/iju.12348

30. Ito Y, Udo K, Vertosick EA. Clinical usefulness of prostate and tumor volume related parameters following radical prostatectomy for localized prostate cancer. J Urol. 2019;201(3):535-540. doi:10.1016/j. juro.2018.09.060

31. Chen ME, Johnston D, Reyes AO, Soto CP, Babaian RJ, Troncoso P. A streamlined three-dimensional volume estimation method accurately classifies prostate tumors by volume. Am J Surg Pathol. 2003;27(10):1291-1301. doi:10.1097/00000478-200310000-00001

32. Marks RA, Lin H, Koch MO, Cheng L. Positive-block ratio in radical prostatectomy specimens is an independent predictor of prostate-specific antigen recurrence. Am J Surg Pathol. 2007;31 (6):877-881. doi:10.1097/01.pas.0000213429.61374.4f 
33. Renshaw AA, Chang H, D'Amico AV. Estimation of tumor volume in radical prostatectomy specimens in routine clinical practice. $\mathrm{Am}$ J Clin Pathol. 1997;107(6):704-708. doi:10.1093/ajcp/107.6.704

34. Müller G, Rieken M, Bonkat G, et al. Maximum tumor diameter adjusted to the risk profile predicts biochemical recurrence after radical prostatectomy. Virchows Arch. 2014;465(4):429-437. doi:10.1007/s00428-014-1643-1
35. Cookson MS, Aus G, Burnett AL, et al. Variation in the definition of biochemical recurrence in patients treated for localized prostate cancer: the American Urological Association Prostate Guidelines for Localized Prostate Cancer Update Panel report and recommendations for a standard in the reporting of surgical outcomes. J Urol. 2007;177 (2):540-545. doi:10.1016/j.juro.2006.10.097

\section{Publish your work in this journal}

Research and Reports in Urology is an international, peer-reviewed, open access journal publishing original research, reports, editorials, reviews and commentaries on all aspects of adult and pediatric urology in the clinic and laboratory including the following topics: Pathology, pathophysiology of urological disease; Investigation and treatment of urological disease; Pharmacology of drugs used for the treatment of urological disease. The manuscript management system is completely online and includes a very quick and fair peer-review system, which is all easy to use. Visit http://www.dovepress.com/ testimonials.php to read real quotes from published authors. 